\title{
Histochemical Assessment of AgNORs in Cutaneous Neoplasms of Cattle
}

\author{
S. Vijaykumar ${ }^{1}$, A.W. Lakkawar ${ }^{1}$, R. Kumar ${ }^{1}$, R. Dhodapkar ${ }^{2}$ and M.G. Nair ${ }^{1 *}$ \\ ${ }^{1}$ Department of Veterinary Pathology, Rajiv Gandhi Institute of Veterinary Education and \\ Research, Puducherry-605009, India \\ ${ }^{2}$ Department of Microbiology, Jawaharlal Institute of Postgraduate Medical Education and \\ Research, Puducherry-605006, India \\ *Corresponding author
}

\section{A B S T R A C T}

\section{Keywords \\ Histochemical assessment, AgNORs Cutaneous neoplasms}

\section{Article Info}

Accepted: 06 June 2018 Available Online: 10 July 2018
A prospective study was conducted on twenty five cutaneous growths from various breeds of cattle were assessed for cellular proliferation by employing AgNORs (Argyrophilic Nucleolar Organizing Regions) staining method. Histochemical assessment of AgNORs revealed a significantly higher count in malignant neoplasms in comparison to benign neoplasms. The AgNOR counts in cutaneous and teat papillomas ranged from 1.98 to 2.68 with an average count of 2.33. The NOR counts was highest in squamous cell carcinoma (6.12), followed by melanoma (3.24), fibroma (3.16) and trichoepithelioma (2.31). The study concluded that the assessment of AgNORs was found to be very useful to differentiate between benign, malignant and borderline cases of cutaneous neoplasms.

\section{Introduction}

The neoplastic conditions affecting them must be given emphasis as they may lead to poor body condition, decreased production, culling of animals and mortality. Cattle and buffalo in India are commonly affected by a variety of neoplasms including horn cancer, eye cancer, lymphosarcoma, ethmoid carcinoma, urinary bladder cancer and cutaneous neoplasms and warts. Incidence of skin neoplasms has relatively increased in cattle and they are, indicating the second in place, after dogs (Madewell et al., 1978). Neoplasms involving the skin and subcutaneous tissue occur in cattle, and are the most commonly diagnosed neoplasms in veterinary practice. Appropriate diagnosis and prompt prognosis are very important to select suitable line of treatment for any kind of neoplasms. Although, there are several diagnostic and prognostic markers available for most of the neoplastic disorders but their use is limited at field level, particularly in veterinary practice. The assessment of cell proliferation markers is very helpful tool to ascertain malignancy status of any neoplasms. One of the most widely used cell proliferation marker in 
veterinary practice is AgNOR (Argyrophilic Nucleolar Organizer Regions). The silver stain was originally used to demonstrate the NORs of chromosomes, to evaluate their function, and to identify chromosomes in cytogenetic preparations. This technique was subsequently popularized, especially by Crocker and associates (1989), and the staining protocol that Crocker described has been used by most workers in the field. The number of NORs expressed in a tissue was related to the rate of cell proliferation, differentiation, and to neoplastic transformation. Crocker et al., 1989 proposed this technique and the staining protocol designed are being extensively followed to study rate of cell proliferation. Lindner, (1993) have suggested that the technique has practical utility in diagnostic pathology for demonstration of neoplastic potential and for evaluating the prognosis and aggressiveness of malignant neoplasms. NORs can be demonstrated in tissue sections by staining their associated proteins with colloidal silver and these silver-stained reaction products represent the argyrophilic nucleolar organizer regions (AgNOR). NORs reflect protein synthesis and are known to increase in number during malignancies. Smith et al., (1988) and Dervanet al., (1989) have shown that AgNOR counts can be used to differentiate between benign and malignant lesions, whereas a few authors (Leek et al., 1991; Fallowfield et al., 1989) have stated that it is the morphological characteristics of AgNOR that is more informative than their absolute numbers.

Nucleolar organizer regions (NORs) are loops of DNA present in the nucleoli and contain genes that code for ribosomal RNA (rRNA) which are transcribed by RNA polymerase I. Certain argyrophilic proteins, called NORassociated proteins (NORAPs), are associated with this gene. These argyrophilic nuclear oragnizer region proteins said to accumulate in highly proliferating cells of tumours due to its segregation during transcription which could be demonstrated as black dots with silver staining on routine paraffin embedded sections and called as argyrophilic nucleolar organizer regions (AgNOR). The number of interphase AgNOR in continuously proliferating cells had been strictly related to the rapidity of cell proliferation (Trere, 2000).

Measurement and enumeration of AgNORs have been useful in prognostic the behaviour of a variety of neoplasms of humans, particularly in instances where mitotic rate is a poor determinant of eventual recurrence of metastasis. AgNORs have been less useful in epithelial neoplasms, in which there is a relatively high mitotic rate in the cell type of origin as compared with sarcomas.

\section{Materials and Methods}

Twenty five cutaneous growths from various breeds of cattle were assessed for cell proliferation potential employing AgNORs (Argyrophilic Nucleolar Organizing Regions) staining. Formalin fixed paraffin embedded tissue sections were stained according to the protocol of the standardized AgNOR method (Jelesijevic et al., 2003) with little modification. The sections were deparaffinised in two changes of xylene for 10 min each, hydrated in graded alcohol and washed in ultrapure water for 5 minutes. Pretreatment of the sections was done by pressure cooking for 20 minutes in $10 \mathrm{mM}$ citrate buffer, $\mathrm{pH} 6.0$ and sections were cooled to room temperature, and washed for 2 minutes in ultrapure water. The pre-treated sections were stained with two parts of freshly prepared 33\% silver nitrate solution mixed with one part of $2 \%$ gelatine in $1 \%$ formic acid for 30-45 minutes (depending on the staining intensity of each tissue block) at room temperature in the dark in a humidified chamber. The stained sections were rinsed thoroughly with ultrapure water, and fixed in 
$2 \%$ sodium thiosulfate solution for 5 minutes. Finally, the sections were washed in distilled water, dehydrated in graded alcohol, cleared in xylene and mounted with DPX.

\section{Quantification of AgNOR}

Quantification of AgNOR was performed with the Image-Pro PLUS 6.0 software (Media Cybernetics, USA). On each slide, 250 neoplastic cells were counted within the most typical for the histopathological diagnosis. The average number of AgNOR dots per nuclei was calculated and used for analysis. The results were compared between different benign and malignant neoplasms to assess their proliferative activity and level of malignancy.

\section{Image analysis}

Image analysis was carried out on all AgNOR stained sections. All images were captured using a binocular Olympus BX41 microscope (Olympus Co., Japan) fitted with an Evolution LC digital camera. The digital images were analysed using a semi-automated image processing and analysis software, Image-Pro ${ }^{\circledR}$ PLUS 6.0 (media Cybernetics, USA). The software performs automatic measurement of areas defined using an interactive threshold editing functions.

\section{Results and Discussion}

Nucleolar organiser regions (NORs) are defined as nucleolar components containing a set of argyrophilic proteins, which are selectively stained by silver methods. After silver staining, the NORs can be easily identified as black dots exclusively localised throughout the nucleolar area, and are called "AgNORs". The NORs argyrophilia is due to a group of nucleolar proteins, which have a high affinity for silver (AgNOR proteins). Moreover, in tumour tissues AgNOR protein expression was found to be strictly related to the cell duplication rate. The "AgNOR" method has been applied in tumour pathology for both diagnostic and prognostic purposes (Crocker and Murray, 2003).

In the present study following silver staining, the AgNOR appeared as discrete dots of varying sizes, seen as single to multiple dots in center or towards periphery of the nucleus (Fig. 1, 2, 3 and 4). The AgNOR results for benign and malignant neoplasms are depicted in Table 1. Highest AgNOR counts were recorded in squamous cell carcinoma (6.12) followed by melanoma (3.24). The lowest count was recorded by trichoepithelioma (2.31) followed by fibroma (3.16) and fibropapilloma (2.68). Some of the benign neoplasms including a solitary case of papilloma and fibroma, which showed tendency towards malignancy, expressed very high AgNOR counts. AgNOR counts of malignant neoplasms differed significantly $(p<0.01)$ from benign neoplasms. Benign neoplasms had $\mathrm{AgNOR}$ values ranging from 2.68 to 3.16 per nucleus. The average AgNOR counts per cell of all the cutaneous neoplasms and cutaneous wart recorded in this study are depicted in Table 1 and 2.

AgNOR counts of malignant neoplasms differed significantly $(\mathrm{p}<0.01)$ from benign neoplasms. Benign neoplasms had AgNOR values ranging from 2.68 to 3.16 per nucleus.

The observations in the present study that among the various neoplasms; higher AgNOR count was recorded in squamous cell carcinoma followed by fibroma. The AgNOR counts of malignant neoplasms were higher in comparison to benign a neoplasm, which was in accordance to the earlier report (Akthar et al., 2004; Gulia et al., 2011 and Karki et al., 2012). A higher AgNOR count in malignant neoplasms might be attributed to high concentration of interphase AgNOR proteins in the rapidly proliferating cells (Bratulic, 1996). 
Table.1 AgNOR counts in benign and malignant neoplasms

\begin{tabular}{|c|c|c|c|}
\hline Benign neoplasms & AgNOR & Malignant neoplasms & AgNOR \\
\hline Papilloma & 2.68 & Squamous cell carcinoma & 6.12 \\
\hline Trichoepithelioma & 2.31 & & \\
\hline Melanoma & 3.24 & & \\
\hline Fibroma & 3.16 & & \\
\hline
\end{tabular}

Table.2 AgNOR counts in papilloma cases

\begin{tabular}{|c|c|c|}
\hline S.NO & Papilloma Case No & AgNOR \\
\hline $\mathbf{1 .}$ & BP-4 & 2.12 \\
\hline $\mathbf{2 .}$ & BP-10 & 2.25 \\
\hline $\mathbf{3 .}$ & BP-17 & 2.11 \\
\hline $\mathbf{4 .}$ & BP-23 & 2.67 \\
\hline $\mathbf{5 .}$ & BP-29 & 2.05 \\
\hline $\mathbf{6 .}$ & BP-32 & 2.57 \\
\hline $\mathbf{7 .}$ & BP-39 & 2.26 \\
\hline $\mathbf{8 .}$ & BP-48 & 1.98 \\
\hline $\mathbf{9 .}$ & BP-55 & 2.23 \\
\hline $\mathbf{1 0 .}$ & BP-59 & 2.68 \\
\hline $\mathbf{1 1 .}$ & BP-64 & 2.29 \\
\hline $\mathbf{1 2 .}$ & BP-71 & 2.52 \\
\hline $\mathbf{1 3 .}$ & BP-80 & 2.45 \\
\hline $\mathbf{1 4 .}$ & BP-89 & 2.18 \\
\hline $\mathbf{1 5 .}$ & BP-93 & 2.65 \\
\hline & & \\
\hline
\end{tabular}


Figure.1 Papilloma showing nucleolar organizer regions (AgNOR) as discrete black dots of uniform size inside the nuclei. Silver stain x 1000

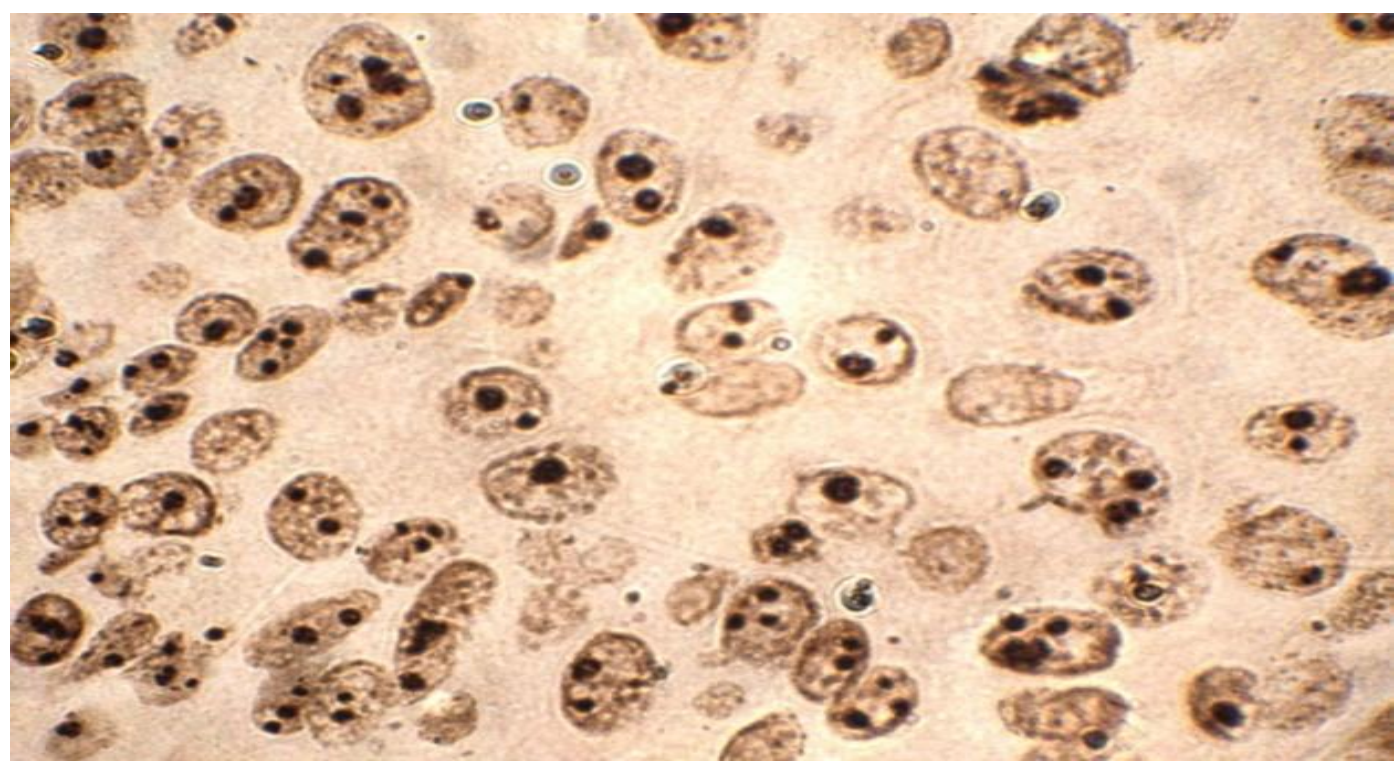

Figure.2 Squamous cell carcinoma showing nucleolar organizer regions(AgNOR) as discrete black dots of variable size inside the nuclei. Silver stain x 1000

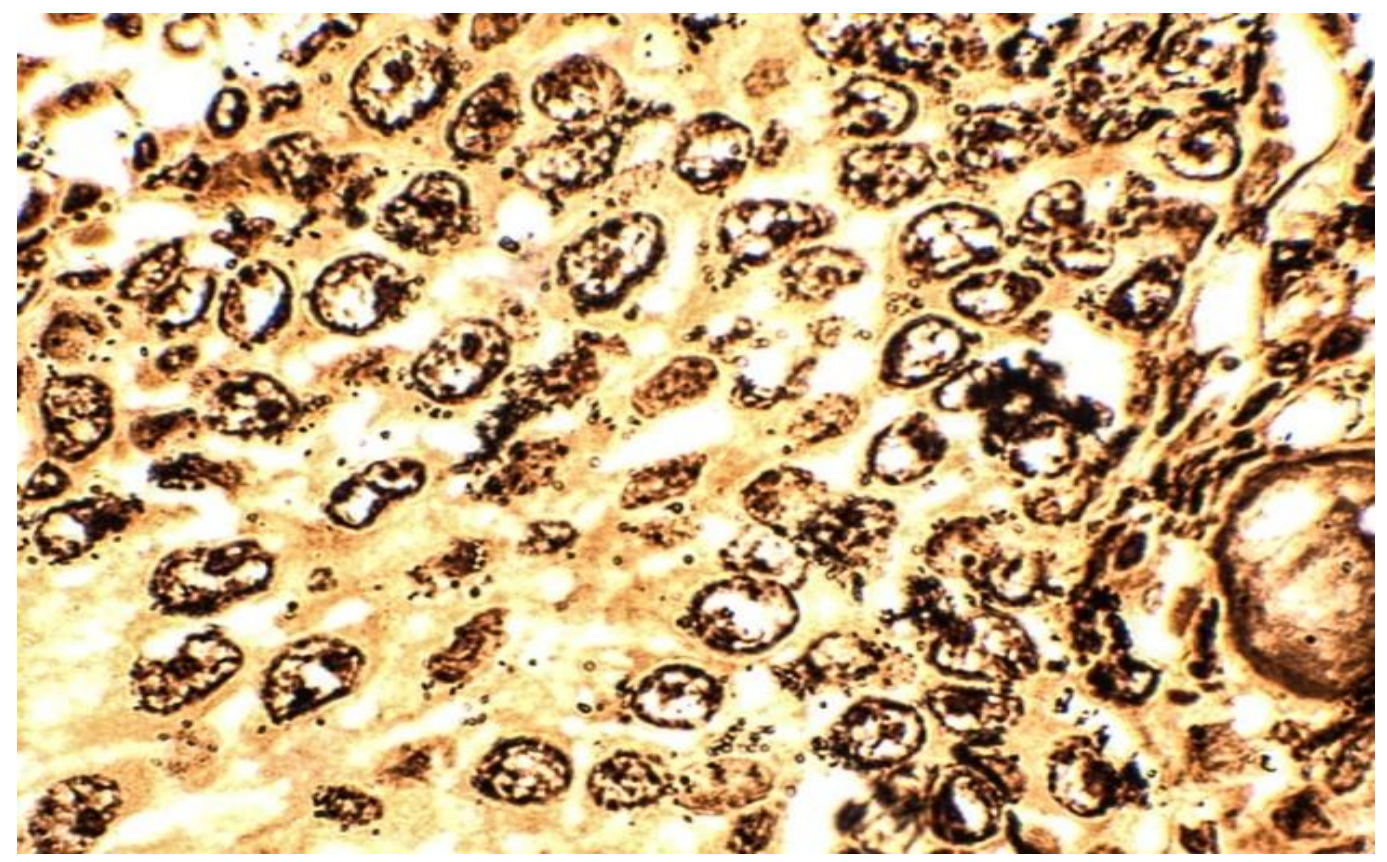


Figure.3 Fibroma showing nucleolar organizer regions (AgNOR) as discrete black dots of variable size inside the nuclei. Silver stain x 1000

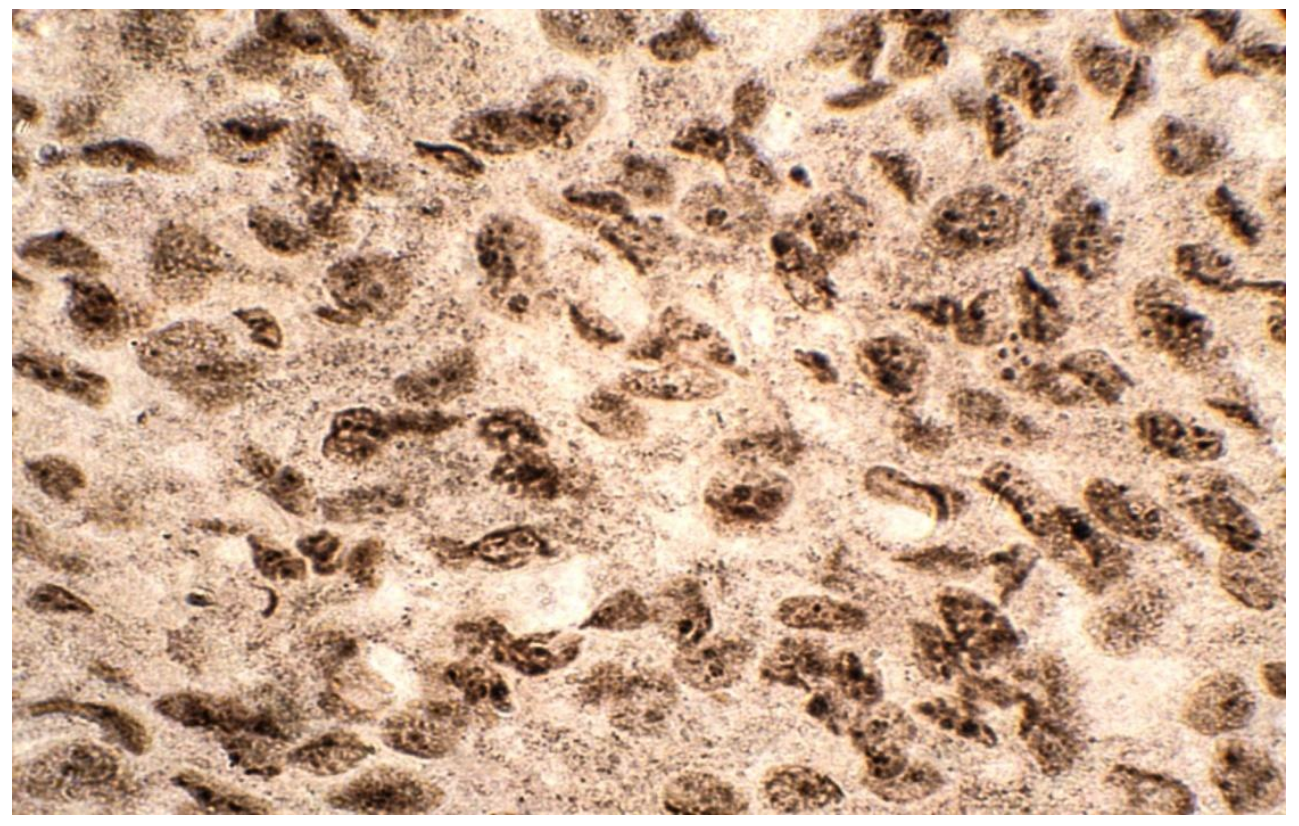

Figure.4 Trichoepithelioma showing nucleolar organizer regions (AgNOR) as discrete black dots of variable size inside the nuclei. Silver stain x 1000

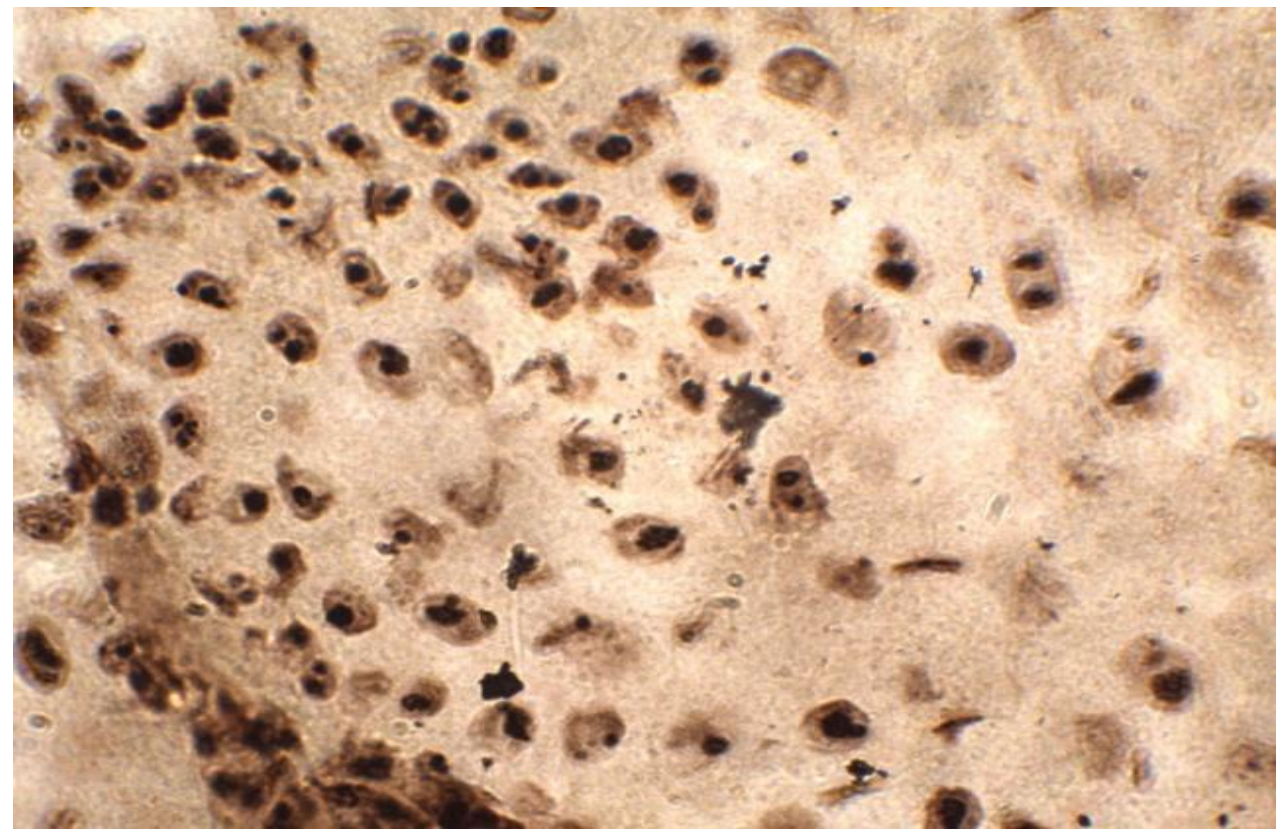


The utility of AgNOR as a proliferation marker in cutaneous skin neoplasms has been reported by Lindner (1993). The AgNOR staining in the present study was found to be useful prognostic marker to assess the rapidity of cell proliferation. The NOR's appeared as discrete dots of varying sizes, ranging from single to multiple dots either in the center or towards the periphery of the nucleus in cases of benign neoplasm (papilloma). In malignant neoplasm (squamous cell carcinoma), the NOR's were disturbed as minute dots throughout nucleoplasm giving a granular appearance to the nuclei. The expression of NORs was relatively higher in malignant neoplasm (squamous cell carcinoma) compared to the other begin neoplasms.

On perusal of the literature, AgNOR count as a marker for Palanivelu (2011) highlighted the utility of AgNOR count to study cellular proliferation in cutaneous papilloma in dogs, where in 2 out of 7 cases were characterized by highly proliferative spinosal cell layer with moderate number of mitotic figures and a higher AgNOR count showed a tendency towards malignant squamous transformation, suggesting the possibility of early stage of cutaneous squamous cell carcinoma.

A higher AgNOR count observed in the malignant neoplasm might be attributed to a higher concentration of interphase AgNOR proteins in the rapidly proliferating cells (Bratulic, 1996). The AgNOR counts of malignant neoplasms were reported to be higher in comparison to benign neoplasm in human patients (Akthar et al., 2004; Gulia et al., 2011).

\section{Acknowledgements}

The authors express sincere gratitude and thanks to the Dean, Rajiv Gandhi College of Veterinary and Animal Sciences, Pondicherry, India for providing necessary facilities to conduct the research.

\section{References}

Akhtar K, Mehdi G, Maheshwari V, Siddiqui SA and Sharma R (2004). Diagnostic and prognostic significance of AgNOR counts in radiotherapy treated squamous cell carcinoma of the cervix. J. Obstet. Gynecol. India., 55: 163-166.

Crocker J, Boldy DAR and Egan MJ (1989). How should we count AgNORs? Proposal for a standardized approach. J. Pathol., 158: 185-188.

Crocker J and Murray PG (2003). Molecular Biology in Cellular Pathology. John Wiley \& Sons, Ltd, USA

Dervan PA, Gilmartin LG; Loftus BM and Carney DN (1989). Argyrophilic nucleolar organizer region counts correlate with Ki67 scores. Am J Clin Pathol.,92:401-407.

Fallowfield ME and Cook MG (1989). The value of nucleolar organizer region staining in the differential diagnosis of borderline melanocytic lesions. Histopathology., 14:299-304.

Gulia S P, Sitaramam E and Reddy K P (2011).The role of silver staining nucleolar organiser regions (AgNORs) in lesions of the oral cavity. J. Clin. Diag. Res. 5: 1011-1015.

Jelesijevic T, Jovanovic M, Knezevic Milijana and Aleksic-Kovacevic Sanja (2003). Quantitative and qualitative Analysis of AgNOR in Benign and Malignant canine Mammary Gland Tumours. Act. Vet. 53: 353-360.

Johnson GC, Miller MA and Ramos-Vara JA (1995). Comparison of argyrophilic nucleolar organizer regions (AgNORs) and mitotic index in distinguishing benign from malignant canine smooth muscle tumours and in separating inflammatory hyperplasia from neoplastic lesions of the urinary bladder mucosa. J. Vet. Diagn. Invest. 7: 127-136. 
Leek RD, Alison MR and Sarraf CE (1991).Variations in the occurrence of silver staining nucleolar organizer regions (AgNORs) in nonproliferating and proliferating tissues. J Pathol.,165: 43-51.

Lindner LE (1993). Improvement in the silver-staining technique for nucleolar organizer regions (AgNOR). J.Histochem.Cytochem., 41: 439-445. Madewell BR and Theilen GH (1978).
Tumours of the Skin and Subcutaneous Tissues, Veterinary Cancer medicine, Lea \& Febiger, Philadelphia, USA.

Smith R and Crocker J (1988).Evaluation of nucleolar organizer region-associated proteins in breast malignancy. Histopathology., 12: 113-25.

Trere D. (2000). AgNOR staining and quantification. Micron., 31: 127-131.

\section{How to cite this article:}

Vijaykumar, S., A.W. Lakkawar, R. Kumar, R. Dhodapkar and Nair, M.G. 2018. Histochemical Assessment of AgNORs in Cutaneous Neoplasms of Cattle. Int.J.Curr.Microbiol.App.Sci. 7(07): 523-530. doi: https://doi.org/10.20546/ijcmas.2018.707.064 